\title{
Cyclophosphamide protects against myocardial ischemia/reperfusion injury in rats: One of the therapeutic targets is high sensitivity C-reactive protein
}

Qi-qi Wang, MD, Yuan-gang Qiu, MD, Yu-juan Zhu, MD, Jian-hua Zhu, MD, Li-hong Wang, MD, PhD, Xiao-sheng Hu, MD, PhD, Shen-jiang $\mathrm{Hu}, \mathrm{MD}$, PhD, Liang-rong Zheng, MD, PhD, Qian-min Tao, MD, Fu-rong Zhang, MD, and Yun Zhang, MD

Objective: Cyclophosphamide has a role of decreasing high-sensitivity C-reactive protein in the treatment of autoimmune disorders. The effect of cyclophosphasmide on high-sensitivity C-reactive protein was investigated in myocardial ischemia/reperfusion rat.

\begin{abstract}
Methods: Open-chest rats were submitted to 30 minutes of ischemia and followed for 3, 12, or 24 hours of reperfusion. All 72 rats survived and were divided into sham, ischemia/reperfusion (I/R) and cyclophosphamide groups, and each group included 3 time-point subgroups $(3,12$, and 24 hours; $n=8$ for each subgroup). Cyclophosphamide $\left(0.75 \mathrm{~g} / \mathrm{m}^{2}\right)$ or saline was intraperitoneally administrated in the cyclophosphamide or I/R group. A polyethylene tube was inserted into the left ventricular cavity to detect left ventricular systolic pressure, left ventricular end-diastolic pressure, and maximum rate of rise or fall of left ventricular pressure. In the end, blood was collected for detection of high-sensitivity C-reactive protein, and hearts were harvested for histopathologic assessment and infarct size determination.

Results: Compared with the I/R group, rats treated with cyclophosphamide showed a significant recovery in myocardial function with improved left ventricular systolic pressure $(88.27 \pm 3.78 \mathrm{vs} 68.62 \pm 3.78 \mathrm{~mm} \mathrm{Hg}$ at $3 \mathrm{hours}$, $92.04 \pm 3.77$ vs $63.74 \pm 4.87 \mathrm{~mm} \mathrm{Hg}$ at 12 hours, and $90.41 \pm 3.98$ vs $64.21 \pm 4.88 \mathrm{~mm} \mathrm{Hg}$ at 24 hours; $P<.05$, respectively). Left ventricular end-diastolic pressure and maximum rate of rise or fall of left ventricular pressure also had similar trends. Infarct size was reduced $(26.1 \% \pm 0.4 \%$ vs $40.4 \% \pm 0.4 \%$ at 3 hours, $21.6 \% \pm 0.4 \%$ vs $49.9 \% \pm 0.4 \%$ at 12 hours, and $21.6 \% \pm 0.4 \%$ vs $40.0 \% \pm 0.4 \%$ at 24 hours; $P<.01$, respectively). Histopathologic damage score was attenuated ( $1.83 \pm 0.14$ vs $2.17 \pm 0.14$ at 3 hours, $2.33 \pm 0.14$ vs $3.17 \pm 0.14$ at 12 hours, and $2.83 \pm 0.14$ vs $3.83 \pm 0.14$ at 24 hours; $P<.01$, respectively). Plasma high-sensitivity C-reactive protein concentration was significantly reduced $(29.28 \pm 0.51 \mathrm{vs} 32.26 \pm 0.51 \mathrm{ng} / \mathrm{mL}$ at 3 hours, $29.06 \pm 0.50 \mathrm{vs}$ $31.8 \pm 0.51 \mathrm{ng} / \mathrm{mL}$ at 12 hours, and $28.61 \pm 0.51 \mathrm{vs} 31.86 \pm 0.51 \mathrm{ng} / \mathrm{mL}$ at $24 \mathrm{~h} ; P<.01$, respectively).
\end{abstract}

Conclusion: Cyclophosphamide protects myocardial ischemia/reperfusion injury in the rat with a decrease in plasma concentration of high-sensitivity $\mathrm{C}$-reactive protein.

Cyclophosphamide has been used in the treatment of autoimmune disorders. ${ }^{1}$ An early decrease in C-reactive protein (CRP) concentration was found in patients with autoimmune disease after treatment with intravenous cyclophosphamide. ${ }^{2}$ High-sensitivity C-reactive protein (hs-CRP) is part of the nonspecific acute-phase response protein and is one of the most sensitive markers ${ }^{3}$ of systemic inflammation and tissue damage, along with acute myocardial infarction and ischemia/reperfusion (I/R) injury. ${ }^{4,5}$ We hypothesized

\footnotetext{
From the Department of Cardiology, the First Affiliated Hospital, College of Medicine, Zhejiang University, Institute of Cardiology, Zhejiang University, Hangzhou, People's Republic of China.

Supported by grants from the Department of Science and Technology, Zhejiang Province (2004c33025) and the Project of Medical Science Research Foundation of Zhejiang Province (2006a048, 2006QN010), People's Republic of China.

Received for publication Jan 4, 2008; revisions received Feb 29, 2008; accepted for publication April 13, 2008.

Address for reprints: Yuan-gang Qiu, MD, Department of Cardiology, the First Affiliated Hospital, College of Medicine, Zhejiang University, 79 Qingchun Road, Hangzhou, 310003, P.R.China (E-mail: qiuyuangang1@yahoo.com.cn).

J Thorac Cardiovasc Surg 2009;137:991-6

$0022-5223 / \$ 36.00$

Copyright (c) 2009 by The American Association for Thoracic Surgery

doi:10.1016/j.jtcvs.2008.04.033
}

that myocardial I/R injury could be partially ameliorated with cyclophosphamide treatment by decreasing hs-CRP in the rat.

\section{MATERIALS AND METHODS}

The Animal Care and Use Committee of Zhejiang University approved all procedures, and the investigation conformed to the "Guidelines for the Care and Use of Laboratory Animals," which was published by the National Institutes of Health (NIH Publication No. 85-23, revised 1996).

\section{Animal Model}

We used $70 \%$ povidone-iodine to sterilize the skin and an autoclave to sterilize surgical instruments and drapes by high pressure/high temperature steam; $2 \%$ glutaraldehyde was used for surgical scrub. We wore sterile gloves and a surgical mask, then disinfected the operating table before surgery. Adult male Sprague-Dawley rats (250-275 g, provided by Shanghai Laboratory Animal Center, Chinese Academy of Sciences) were anesthetized with chloral hydrate $(400 \mathrm{mg} / \mathrm{kg})$ through an intraperitoneal injection. The animals were placed in a supine position with their paws and upper central incisors taped to the operating table. An endotracheal tube was inserted through the mouth into the trachea. Artificial respiration was maintained through the respirator with an inspiratory/expiratory ratio of $1: 2$, a frequency of 65 strokes/min, and a tidal volume of $15 \mathrm{~mL}$ to maintain normal arterial oxygen tension, carbon dioxide tension, and $\mathrm{pH}$. We clipped the hair with 


$$
\begin{aligned}
& \text { Abbreviations and Acronyms } \\
& \begin{aligned}
\mathrm{CRP} & =\mathrm{C} \text {-reactive protein } \\
\pm \mathrm{dp} / \mathrm{dt}_{\max }= & \text { maximum rate of rise or fall of left } \\
& \text { ventricular pressure } \\
\mathrm{hs}-\mathrm{CRP}= & \text { high-sensitivity C-reactive protein } \\
\mathrm{I} / \mathrm{R} & =\text { ischemia/reperfusion } \\
\mathrm{LVEDP} & =\text { left ventricular end-diastolic pressure } \\
\mathrm{LVSP} & =\text { left ventricular systolic pressure }
\end{aligned}
\end{aligned}
$$

a No. 40 clipper blade and disinfected the skin. We draped the animal with sterile drapes to avoid contamination of the incision and exposed the surgical field. The middle skin incision was extended from the sternal angle down to the xiphoid. The left pectoral muscles were dissected longitudinally to expose the left third and fourth ribs. A parasternal incision was made to open the chest by dissecting the intercostal muscles between the left third and fourth ribs and kept open by a stent without cutting the ribs. A 7-0 silk suture was passed underneath the left anterior descending coronary artery (2-3 $\mathrm{mm}$ inferior to the left auricle) with an occluder fixed onto the left anterior descending coronary artery and tied. Coronary artery ligation was achieved and reperfusion was induced by releasing the tie. Significant electrocardiographic changes, including widening of the QRS complex and elevation of the ST segment, and color changes of the area at risk were considered indicative of successful coronary occlusion and reperfusion. Warmed saline solution $(1 \mathrm{~mL})$ was administered intraperitoneally in case of dehydration after the operation. The chest was closed in layers, and the animal was weaned from the respirator when spontaneous breathing began. ${ }^{6}$ The rat was placed back in a separate sterile pack for no more than 5 animals.

\section{Experimental Protocol}

Rats were subjected to $0.75 \mathrm{~g} / \mathrm{m}^{2}$ cyclophosphamide ${ }^{7}$ (Jiangsu Hengrui Medicine Co Ltd, NanJing, China) or saline through intraperitoneal injection before surgery (about 10-20 minutes), followed by 30 minutes of left ventricular normothermic ischemia and 3,12, or 24 hours of reperfusion in the cyclophosphamide group or I/R group ( $\mathrm{n}=8$ in each subgroup). The dose of cyclophosphamide that we selected was about $20 \%$ higher than the commonly used dose in studies of patients with rheumatoid arthritis or systemic vasculitis but still within the safe range, for rats tolerate a higher dosage than human beings. Furthermore, the present dose had been shown to be effective and widely used in rat experiments. ${ }^{7}$ In the sham group, saline was intraperitoneally injected before the operation. The silk suture crossed without ligation and the rat did not receive I/R. In the I/R group, saline was intraperitoneally injected before operation, and the rat received I/R. In the cyclophosphamide group, cyclophosphamide was intraperitoneally injected before the operation, and the rat received I/R. Hemodynamic parameters were detected at $0,3,12$, and 24 hours after reperfusion. Blood was collected for hs-CRP detection, and hearts were harvested for histopath- ologic assessment and infarct size determination at the end of reperfusion (Figure 1).

\section{Hemodynamic Assessment}

At the end of reperfusion, rats were anesthetized again, and a polyethylene tube (PE 50; Becton Dickinson Co, Franklin Lakes, NJ) was inserted into the left ventricular cavity via the right common carotid artery. ${ }^{8}$ The pressure was transduced and monitored by a pressure transducer (XingHangXinYe Co Ltd, Beijing, China). Left ventricular systolic pressure (LVSP), end-diastolic pressure (LVEDP) and maximum rate of pressure rise or fall $\left( \pm \mathrm{dp} / \mathrm{dt}_{\max }\right)$ were recorded and programmed by using a biotic signal collection and processing system (MedLab-U/4cs, MeiYi Co Ltd, Nanjing, China).

\section{Assessment of Risk Area and Infarct Size}

After hemodynamic parameters had been recorded, the chest was reopened under artificial respiration. The coronary artery was briefly occluded again through ligation of the tie that remained at the site of the previous occlusion. Immediately, $2 \mathrm{~mL}$ of Evans blue solution (1\%) was infused through the catheter into the beating left ventricular cavity to delineate the ischemic area. After removal of the right ventricle and atria, the left ventricle was cross-sectioned from the apex to the atrioventricular groove into 7 specimens about $1.5 \mathrm{~mm}$ in thickness with a steric heart mould. ${ }^{6}$ These slices were incubated with $2 \%$ triphenyltetrazolium chloride solution $(\mathrm{pH}=$ 7.4) for 15 to 20 minutes at $37^{\circ} \mathrm{C}$ in a dark room. Then the slices were photographed and the image was programmed by the analysis software (Image $\mathrm{J}$ 1.36; Macintosh, National Institute of Mental Health). The risk area was determined by the percentage of the left ventricle unstained by Evans blue dye, and the infarct area was determined by the percentage of triphenyltetrazolium chloride-unstained area to Evans blue-unstained area. ${ }^{6}$

\section{Histopathologic Analysis}

Additional hearts were fixed in $10 \%$ formalin and embedded in paraffin. The paraffin-embedded tissues were sectioned and stained with hematoxylin and eosin and analyzed by light microscopy. An observer blinded to the treatment regimen examined the sections for histopathologic injury from 6 random high-power fields. ${ }^{9}$ The following morphologic criteria ${ }^{10}$ were used to determine the histopathologic damage: score $0=$ no damage; score 1 $($ mild $)=$ interstitial edema and focal necrosis; score 2 (moderate) $=$ diffuse myocardial cell swelling and necrosis; score 3 (severe) = necrosis with the presence of contraction bands, neutrophil infiltration, and capillary compression; and score 4 (highly severe) = widespread necrosis with the presence of contraction bands, neutrophil infiltration, capillary compression, and hemorrhage.

\section{HS-CRP Measurement}

Measurements of hs-CRP were performed by the rat hs-CRP enzymelinked immunosorbent assay kit (RapidBio Lab. Calabasas, Calif) that has been used in a variety of studies. The lowest limit of detection is $0.1 \mathrm{ng} / \mathrm{mL}$.

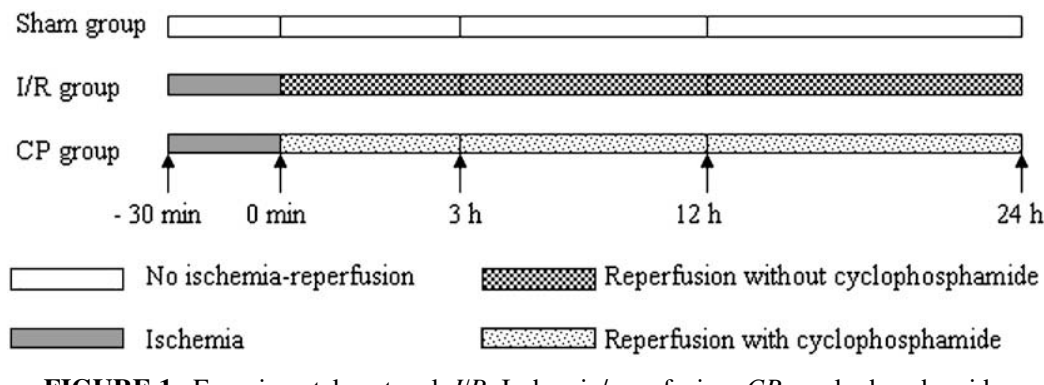

FIGURE 1. Experimental protocol. $I / R$, Ischemia/reperfusion; $C P$, cyclophosphamide. 
TABLE 1. LVSP, LVEDP, $+\mathrm{dp} / \mathrm{dt}_{\max }$, and $-\mathrm{dp} / \mathrm{dt}_{\max }$ in different treatment groups

\begin{tabular}{|c|c|c|c|c|}
\hline Groups & LVSP (mm Hg) & LVEDP (mm Hg) & $+\mathrm{dp} \mathrm{dt}_{\max }(\mathrm{mm} \mathrm{Hg} / \mathrm{s})$ & $-\mathrm{dp} / \mathrm{dt}_{\max }(\mathrm{mm} \mathrm{Hg} / \mathrm{s})$ \\
\hline \multicolumn{5}{|c|}{ Sham group ( $\mathrm{n}=8$ in each subgroup) } \\
\hline $0 \mathrm{~h}$ & $109.97 \pm 5.34$ & $2.16 \pm 0.31$ & $6876.94 \pm 484.22$ & $-7144.32 \pm 742.12$ \\
\hline $3 \mathrm{~h}$ & $104.23 \pm 5.34$ & $2.47 \pm 0.32$ & $6723.68 \pm 484.22$ & $-5945.40 \pm 742.11$ \\
\hline $12 \mathrm{~h}$ & $107.69 \pm 5.34$ & $2.62 \pm 0.34$ & $6820.49 \pm 484.22$ & $-7254.33 \pm 742.12$ \\
\hline $24 \mathrm{~h}$ & $106.35 \pm 5.34$ & $2.57 \pm 0.34$ & $6705.73 \pm 484.22$ & $-5989.14 \pm 742.12$ \\
\hline \multicolumn{5}{|c|}{$\mathrm{I} / \mathrm{R}$ group ( $\mathrm{n}=8$ in each subgroup) } \\
\hline $0 \mathrm{~h}$ & $88.07 \pm 4.88$ & $14.10 \pm 0.78^{*}$ & $5690.86 \pm 442.03$ & $-4655.37 \pm 677.46$ \\
\hline $3 \mathrm{~h}$ & $68.62 \pm 3.78 * \ddagger$ & $14.45 \pm 0.48^{*}$ & $3476.99 \pm 342.40 * \ddagger$ & $-2054.12 \pm 524.76^{*}$ \\
\hline $12 \mathrm{~h}$ & $63.74 \pm 4.87 *$ & $15.13 \pm 0.88^{*}$ & $5182.68 \pm 442.03^{*}$ & $-4070.54 \pm 677.46^{*}$ \\
\hline $24 \mathrm{~h}$ & $64.21 \pm 4.88^{*}$ & $15.50 \pm 0.81^{*}$ & $3608.68 \pm 326.46^{*}$ & $-3032.02 \pm 500.33 *$ \\
\hline \multicolumn{5}{|c|}{ Cyclophosphamide group ( $\mathrm{n}=8$ in each subgroup) } \\
\hline $0 \mathrm{~h}$ & $93.44 \pm 4.22$ & $14.22 \pm 0.61 *$ & $5533.62 \pm 382.81$ & $-4603.57 \pm 586.70$ \\
\hline $3 \mathrm{~h}$ & $88.27 \pm 3.78 * \dagger$ & $14.57 \pm 0.94 *$ & $4675.78 \pm 342.40^{*} \dagger$ & $-4123.71 \pm 524.76^{*}$ \\
\hline $12 \mathrm{~h}$ & $92.04 \pm 3.77 * \dagger$ & $13.00 \pm 0.88^{*} \dagger$ & $5094.34 \pm 342.39 *$ & $-5431.13 \pm 524.76^{*}$ \\
\hline $24 \mathrm{~h}$ & $90.41 \pm 3.98 * \dagger$ & $13.24 \pm 0.79 * \dagger$ & $4992.57 \pm 300.30 * \dagger$ & $-3828.05 \pm 460.24 *$ \\
\hline
\end{tabular}

Expressed as mean \pm SEM. $* P<.01$ compared with sham group of the same time-point. $\dagger P<.05$ compared with $\mathrm{I} / \mathrm{R}$ group of the same time-point. $\ddagger P<.05$ compared with $0 \mathrm{~h}$ in $\mathrm{I} / \mathrm{R}$ group.

\section{Statistical Analysis}

All data were expressed as mean \pm SEM. Analyses were carried out with the SPSS statistical package (version 13.0; SPSS, Inc, Chicago, Ill). Differences between specific means were tested by univariate analysis using general linear models (GLM procedure for SPSS) to perform a 2-factor (or 2-way) analysis of variance.

\section{RESULTS}

Eighty-four rats were subjected to surgery, and the surviving 72 rats were assigned to 3 groups: sham group, I/R group, and cyclophosphamide group. Three rats died during anesthesia, 5 rats died during surgery ( 3 in the I/R group, and 2 in the cyclophosphamide group), and 4 rats died after surgery ( 2 in the I/R group, and 2 in the cyclophosphamide group). The surgical technique used in this study significantly reduced early mortality and also reduced the variation in risk area.

\section{Improved Myocardial Function in} Cyclophosphamide Group (Table 1)

Damaged LVSP, LVEDP and $\pm \mathrm{dp} / \mathrm{dt}_{\max }$ were recorded in the I/R and cyclophosphamide groups and compared with the sham group. LVSP, LVEDP, and $\pm \mathrm{dp} / \mathrm{dt}_{\max }$ became worse at 24 hours in the I/R group, but treatment with cyclophosphamide generated a significant improvement in cardiac function at all time points.

\section{Decrease in Myocardial Infarct Size in Cyclophosphamide Group (Table 2, Figure 2)}

Similarly sized risk areas were observed in both the I/R and cyclophosphamide groups at each time point. The infarct size was reduced $(P<.01$, respectively) by $14.28 \%$ at 3 hours, $28.34 \%$ at 12 hours, and $18.40 \%$ at 24 hours in the group of rats treated with cyclophosphamide compared with the I/R group.

\section{Attenuated Histopathologic Damage in Myocytes (Table 2, Figure 3)}

Three hours after transient I/R, myocardial destruction with focal infiltration of polymorphonuclear neutrophils was evident in the left ventricular free wall. Myocardial damage rapidly progressed after reperfusion, and pathologic

TABLE 2. Risk area, infarct size, damage score, and Hs-CRP concentration in different treatment groups

\begin{tabular}{|c|c|c|c|c|}
\hline Groups & Risk area $(\%)$ & Infarct size $(\%)$ & Damage score & Hs-CRP (ng/mL) \\
\hline \multicolumn{5}{|c|}{ Sham group ( $\mathrm{n}=8$ in each subgroup) } \\
\hline $3 \mathrm{~h}$ & 0 & 0 & 0 & $11.90 \pm 0.54$ \\
\hline $12 \mathrm{~h}$ & 0 & 0 & 0 & $12.13 \pm 0.51$ \\
\hline $24 \mathrm{~h}$ & 0 & 0 & 0 & $11.67 \pm 0.51$ \\
\hline \multicolumn{5}{|c|}{$\mathrm{I} / \mathrm{R}$ group ( $\mathrm{n}=8$ in each subgroup) } \\
\hline $3 \mathrm{~h}$ & $41.4 \pm 0.6$ & $40.4 \pm 0.4$ & $2.17 \pm 0.14$ & $32.26 \pm 0.51$ \\
\hline $12 \mathrm{~h}$ & $41.3 \pm 0.6$ & $49.9 \pm 0.4$ & $3.17 \pm 0.14$ & $31.80 \pm 0.51$ \\
\hline $24 \mathrm{~h}$ & $40.9 \pm 0.6$ & $40.0 \pm 0.4$ & $3.83 \pm 0.14$ & $31.86 \pm 0.51$ \\
\hline \multicolumn{5}{|c|}{ Cyclophosphamide group ( $\mathrm{n}=8$ in each subgroup) } \\
\hline $3 \mathrm{~h}$ & $40.5 \pm 0.6$ & $26.1 \pm 0.4$ & $1.83 \pm 0.14^{*}$ & $29.28 \pm 0.51 *$ \\
\hline $12 \mathrm{~h}$ & $41.0 \pm 0.6$ & $21.6 \pm 0.4$ & $2.33 \pm 0.14^{*}$ & $29.06 \pm 0.50^{*}$ \\
\hline $24 \mathrm{~h}$ & $40.7 \pm 0.6$ & $21.6 \pm 0.4$ & $2.83 \pm 0.14^{*}$ & $28.61 \pm 0.51 *$ \\
\hline
\end{tabular}

Expressed as mean \pm SEM. $* P<.01$ compared with $\mathrm{I} / \mathrm{R}$ group of the same time point. 

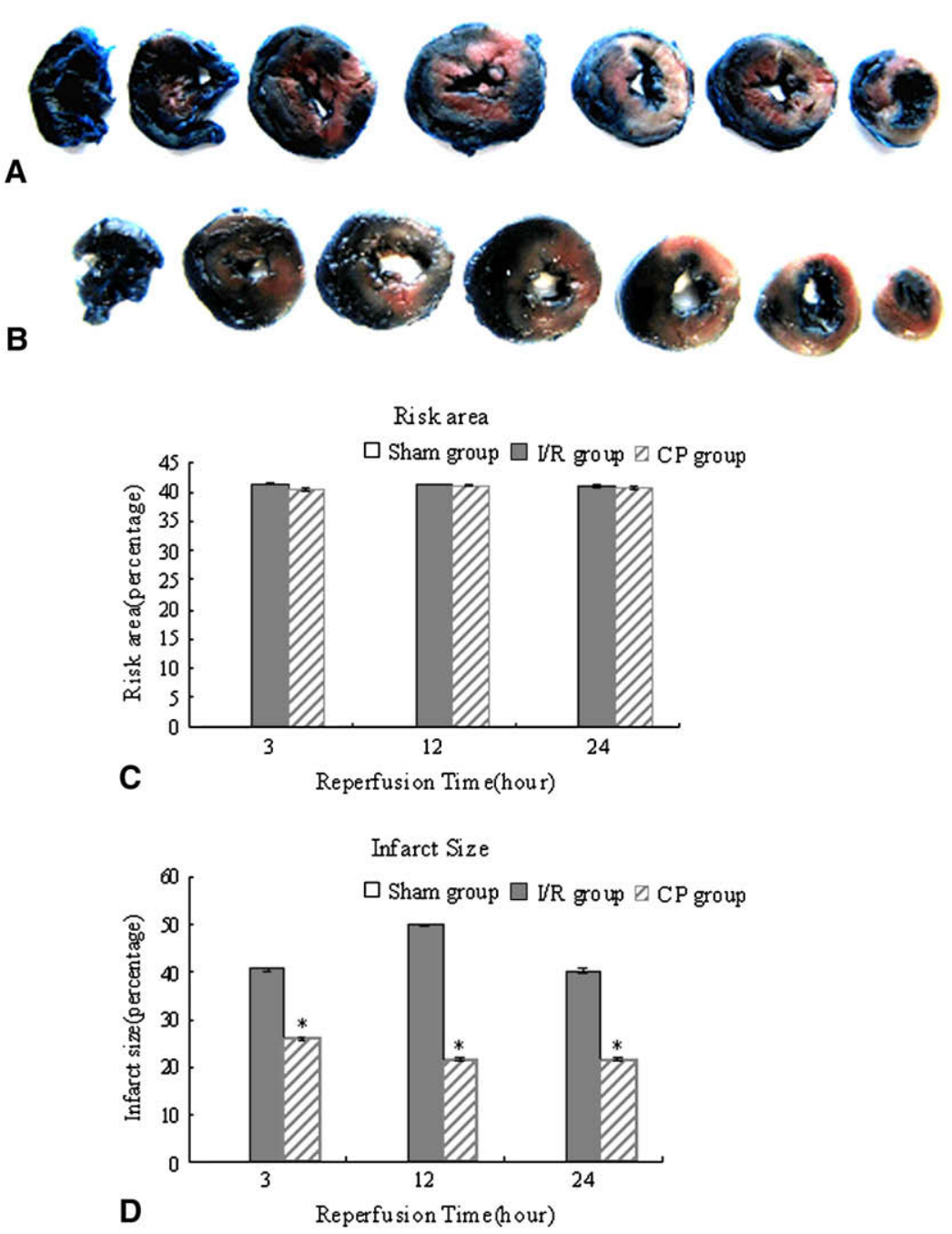

FIGURE 2. Images of infarct area: A, Twelve hours in the ischemia/reperfusion group. B, Twelve hours in the cyclophosphamide group. C, Risk area is expressed as the percentage of Evans blue-unstained area to the whole left ventricular area. D, Infarct size is expressed as the percentage of triphenyltetrazolium chloride-unstained area to Evans blue-unstained area. $I / R$, Ischemia/reperfusion; $C P$, cyclophosphamide. $* P<.01$ compared with $\mathrm{I} / \mathrm{R}$ group at the same time point.

features of the infarct area became apparent by 24 hours after reperfusion with widespread necrosis, the presence of contraction bands, polymorphonuclear neutrophil infiltration, capillary compression, and hemorrhage. In the group with cyclophosphamide treatment, the histologic features were close to normal cardiac structure or mild architectural damage, characterized by interstitial edema and localized necrotic areas. The damage score was reduced in the group of rats treated with cyclophosphamide compared with the control group $(P<.01)$ at 3,12 , and 24 hours.

\section{Concentration of HS-CRP (Table 2)}

Hs-CRP was elevated pronouncedly after reperfusion. Inasmuch as it well represents the increased infarct size and mortality rate of rats, it can be used as a marker of the severity of myocardial injury in myocardial infarction. ${ }^{11-13}$ The levels of hs-CRP were decreased after cyclophosphamide administration at the 3 time points $(P<.01)$.

\section{DISCUSSION}

Our study discovered the novel cardiac protective effect of cyclophosphamide in the rat subjected to I/R. A burst of hs-CRP elevation in plasma was detected after I/R. Cyclophosphamide significantly prevented the secretion of hsCRP. Of interest, these cyclophosphamide-treated rats were associated with reduced infarct size, histopathologic damage score, and preserved myocardial function. The findings are consistent with the notion that activation of hs-CRP might play a role in I/R injury. Furthermore, our data for the first time suggest that cyclophosphamide might mitigate myocardial injury partially by its anti-inflammation effect of hs-CRP downregulation. 

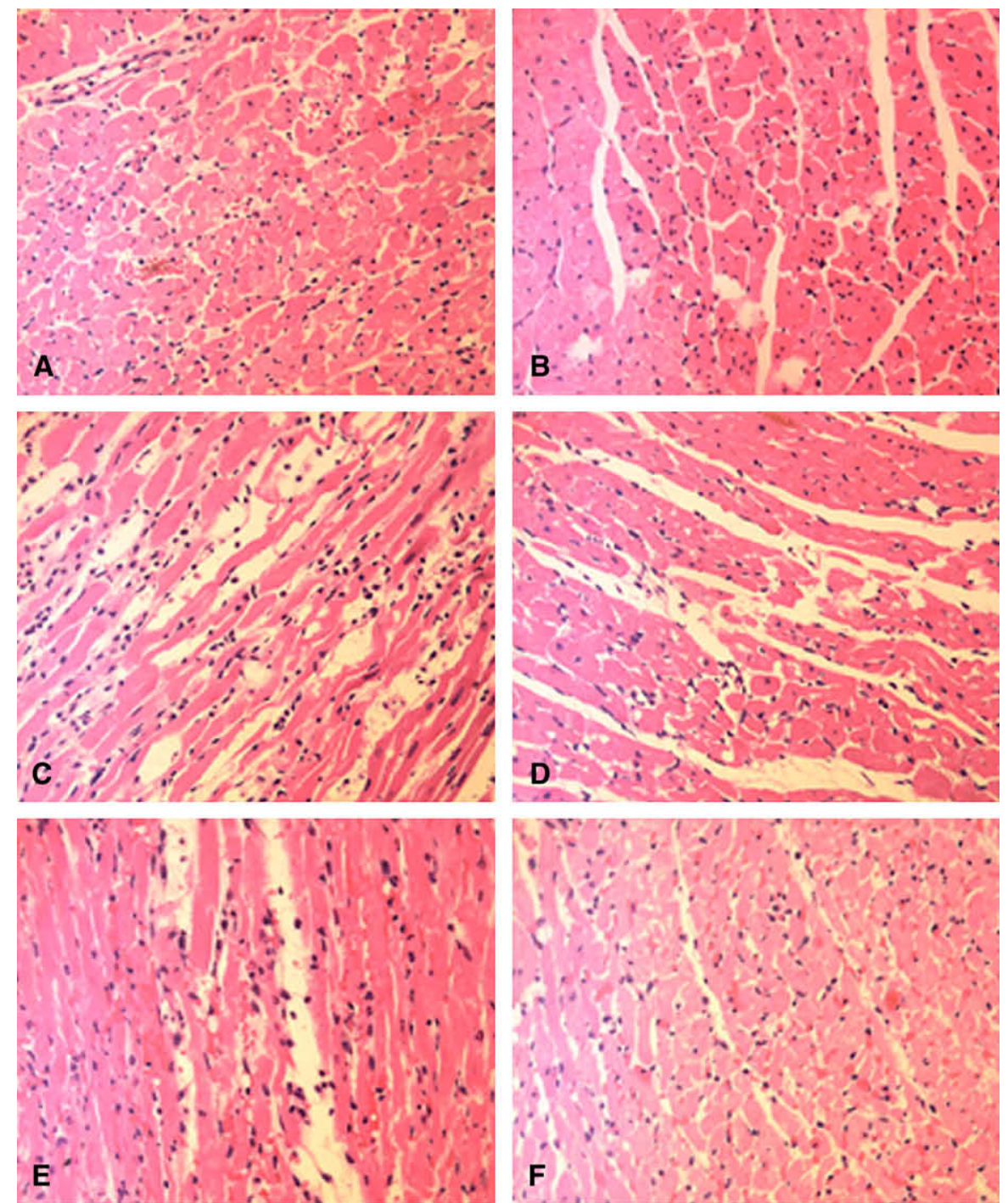

\section{Damage Score}

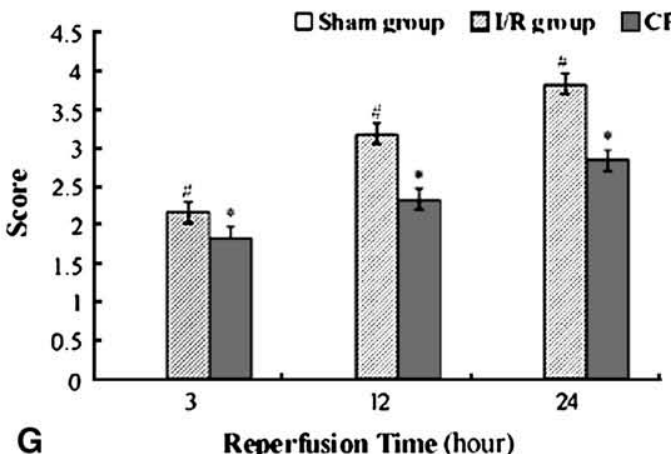

\section{G Reperfusion Time (hour)}

FIGURE 3. Hematoxylin-eosin-stained left ventricular sections from rats treated with cyclophsphamide or saline. Magnification for all images: $400 \times$. A, HE-stained section at 3 hours in I/R group. B, HE-stained section at 3 hours in cyclophosphamide group. C, HE-stained section at 12 hours in I/R group. D, HE-stained section at 12 hours in cyclophosphamide group. E, HE-stained section at 24 hours in I/R group. F, HE-stained section at 24 hours in cyclophosphamide group. G, Damage score. $I / R$, Ischemia/reperfusion, $C P$, cyclophosphamide. $* P<.01$ compared with $\mathrm{I} / \mathrm{R}$ group at the same time point; $\# P<.01$ among different time points in $\mathrm{I} / \mathrm{R}$ groups. 
A previous study had shown hs-CRP elevation after I/R injury, which is significantly elevated by $54 \% 2$ hours after reperfusion and more pronounced (82\% increase) 24 hours after I/R injury. ${ }^{14}$ Such a pathologic state seems to closely resemble the pathophysiology in autoimmune diseases, in which cyclophosphamide is often used as a tool for decreasing CRP. The introduction of cyclophosphamide has radically improved survival in autoimmune diseases. ${ }^{15,16} \mathrm{In}$ this regard, the study suggests the possible use of cyclophosphamide as additional therapeutic treatment in myocardial $\mathrm{I} / \mathrm{R}$ injury.

For many years, hs-CRP has been known as a typical systemic inflammation protein during myocardial $\mathrm{I} / \mathrm{R}$ injury. ${ }^{11-13}$ Many studies suggest that CRP is not only a sensible inflammatory marker, but also should be considered as a direct inflammatory promoter ${ }^{11-13}$ that binds to the damaged myocardial cells, finally increases the infarct size, and worsens the overall postinfarct outcomes. Hack, ${ }^{12}$ Beranek, ${ }^{13}$ and their associates have lately introduced a concept, highlighting the potential pathogenetic importance of CRP binding to nonirremediably damaged cells leading to tissue damage. These works and our present study could suggest that patients with elevated CRP might benefit from anti-inflammatory therapy in myocardial $\mathrm{I} / \mathrm{R}$ injury. Certain medications might be helpful in some patients before a procedure such as percutaneous coronary intervention is performed. There are some medications that may help to decrease hs-CRP. At present, only statins and aspirin have been found to have an effect on decreasing hs-CRP levels. ${ }^{17,18}$ The general anti-inflammatory agent aspirin is already used routinely in patients with coronary disease, and statins have been widely used as well. The anti-inflammatory activity of cyclophosphamide could give the drug a potential benefit in preventing myocardial I/R injury.

Inevitably, possible toxic side effects of cyclophosphamide may limit its clinical application in many diseases. As side effects are usually seen at high doses, cyclophosphamide is a relatively safe drug at low doses. Previous reports have suggested that cyclophosphamide could cause myelosuppression ${ }^{19,20}$ after flushing dose injection during anticancer treatment. Currently, we choose a much lower dose of cyclophosphamide ${ }^{7}$ compared with that in anticancer treatment. At this dose level, it should not cause serious side effects. ${ }^{1,2}$ Itescu and associates ${ }^{21}$ have applied cyclophosphamide pulse therapy in sensitized cardiac allograft recipients, and it proved to be safe and highly effective.

\section{CONCLUSIONS}

Our results demonstrate that cyclophosphamide could mitigate myocardial $\mathrm{I} / \mathrm{R}$ injury in the rat with a decrease in plasma concentration of hs-CRP. These findings could sug- gest a therapeutic benefit by giving anti-inflammatory medication in the setting of myocardial I/R injury.

\section{References}

1. Binotto G, Trentin L, Semenzato G. Ifosfamide and cyclophosphamide: effects on immunosurveillance. Oncology. 2003;65(Suppl. 2):17-20.

2. Martin-Suarez I, D'Cruz D, Mansoor M, Fernandes AP, Khamashta MA, Hughes GR. Immunosuppressive treatment in severe connective tissue diseases: effects of low dose intravenous cyclophosphamide. Ann Rheum Dis. 1997;56: 481-7.

3. Gabay C, Kushner I. Acute phase proteins and other systemic responses to inflammation. N Engl J Med. 1999;340:448-54.

4. de Beer FC, Hind CR, Fox KM, Allan RM, Maseri A, Pepys MB. Measurement of plasma $\mathrm{C}$-reactive protein concentration in myocardial ischemia and infarction. $\mathrm{Br}$ Heart J. 1982;47:239-43.

5. Barrett TD, Hennan JK, Marks RM, Lucchesi BR. C-reactive-protein-associated increase in myocardial infarct size after ischemia/reperfusion. $J$ Pharmacol Exp Ther. 2002;303:1007-13.

6. Yang Z, Zingarelli B, Szabó C. Crucial role of endogenous interleukin-10 production in myocardial ischemia/reperfusion injury. Circulation. 2000;101: 1019-26.

7. Leprán I, Koltai M, Szekeres L. Effect of cyclophosphamide on the acute phase of experimental myocardial infarction in rats. Acta Physiol Acad Sci Hung. 1981;58: 311-5.

8. Wakeno M, Minamino T, Seguchi O, Okazaki H, Tsukamoto O, Okada K, et al. Long-term stimulation of adenosine A2b receptors begun after myocardial infarction prevents cardiac remodeling in rats. Circulation. 2006;114: 1923-32.

9. Hoffmeyer MR, Scalia R, Ross CR, Jones SP, Lefer DJ. PR-39, a potent neutrophil inhibitor attenuates myocardial ischemia-reperfusion injury in mice. Am J Physiol Heart Circ Physiol. 2000;279:2824-8.

10. Zingarelli B, Salzman AL, Szabó C. Genetic disruption of poly (ADP-ribose) synthetase inhibits the expression of P-selectin and intercellular adhesion molecule-1 in myocardial ischemia/reperfusion injury. Circ Res. 1998;83: $85-94$.

11. Pasceri V, Willerson JT, Yeh ET. Direct proinflammatory effect of C-reactive protein on human endothelial cells. Circulation. 2000;102:2165-8.

12. Hack CE, Wolbink G-J, Schalkwijk C, Speijer H, Hermens WT, van den Bosch H. A role for secretory phospholipase A2 and C-reactive protein in the removal of injured cells. Immunol Today. 1997;18:111-5.

13. Beranek JT. C-reactive protein and complement in myocardial infarction and postinfarction heart failure. Eur Heart J. 1997;18:1834-5.

14. Shak PK. Circulating markers of inflammation for vascular risk prediction: are they ready for prime time? Circulation. 2000;101:1758-9.

15. Fauci AS, Katz P, Haynes BF, Wolff SM. Cyclophosphamide therapy of severe systemic necrotizing vasculitis. N Engl J Med. 1979;301:235-8.

16. Hollander D, Manning RT. The use of alkylating agents in the treatment of Wegener's granulomatosis. Ann Intern Med. 1967;67:393-8.

17. Arnaud C, Burger C, Steffens S, Veillard NR, Nguyen TH, Trono D, et al. Statins reduce interleukin-6-induced C-reactive protein in human hepatocytes. Arterioscler Thromb Vasc Biol. 2005;25:1231-6.

18. Ikonomidis I, Andreotti F, Economou E, Stefanadis C, Toutouzas P, Nihoyannopoulos P. Increased proinflammatory cytokines in patients with chronic stable angina and their reduction by aspirin. Circulation. 1999;100: 793-8.

19. Opal SM, Cross AS, Sadoff JC, Collins HH, Kelly NM, Bodmer MW, et al. Efficacy of antilipopolysaccharide and anti-tumor necrosis factor monoclonal antibodies in a neutropenic rat model of Pseudomonas sepsis. J Clin Invest. 1991; 88:885-90.

20. Litt MR, Jeremy RW, Weisman HF, Winkelstein JA, Becker LC. Neutrophil depletion limited to reperfusion reduces myocardial infarct size after 90 minutes of ischemia. Evidence for neutrophil-mediated reperfusion injury. Circulation. 1989;80:1816-27.

21. Itescu S, Burke E, Lietz K, John R, Mancini D, Michler R, et al. Intravenous pulse administration of cyclophosphamide is an effective and safe treatment for sensitized cardiac allograft recipients. Circulation. 2002;105: 1214-9. 